\title{
REVIEW
}

\section{An Update on Treatment and Management of Pediatric Systemic Lupus Erythematosus}

\author{
Amit Thakral · Marisa S. Klein-Gitelman
}

Received: August 9, 2016/Published online: September 30, 2016

(c) The Author(s) 2016. This article is published with open access at Springerlink.com

\section{ABSTRACT}

Systemic lupus erythematosus (SLE) is a chronic multisystem autoimmune disorder in which $20 \%$ of patients are diagnosed in childhood. Childhood-onset SLE is associated with higher morbidity and mortality than adult-onset SLE. The aims of disease management with early immunosuppression are to decrease disease activity and improve quality of life. A multidisciplinary approach is necessary due to the complexity of lupus in pediatric patients. It is important to provide patients with high quality of care and to instill ownership of their disease process from a young age to prepare them to manage this life-long illness. This article reviews current management of SLE in children.

Enhanced content To view enhanced content for this article go to http://www.medengine.com/Redeem/11E6 F0607C5D0675.

A. Thakral ( $\square)$

Ann \& Robert H. Lurie Children's Hospital of Chicago, Northwestern University, Chicago, IL, USA e-mail: athakral@luriechildrens.org

M. S. Klein-Gitelman

Feinberg School of Medicine, Ann \& Robert H. Lurie Children's Hospital of Chicago, Northwestern

University, Chicago, IL, USA
Keywords: Autoimmune; Management; Medication; Pediatric; Rheumatology; Systemic lupus erythematosus; Treatment

\section{INTRODUCTION}

Systemic lupus erythematosus (SLE) is a chronic multisystem autoimmune connective tissue disorder that manifests with a broad spectrum of clinical phenotypes. Approximately $20 \%$ of SLE patients are diagnosed in childhood [1]. The average age of onset of pediatric SLE is between 12 and 14 years and rarely before the age of 5 years [2]. Childhood-onset SLE is associated with greater lifetime morbidity and mortality than adult-onset SLE [3]. Physicians have commonly relied on the American College of Rheumatology (ACR) Criteria for the classification of SLE. These criteria were preliminarily developed in 1971, revised in 1982, and updated in 1997 [4]. A person can be classified as having SLE if at least four of the 11 criteria are present. In order to address limitations of the ACR criteria, the Systemic Lupus International Collaborating Clinics (SLICC) developed the SLICC Classification Criteria in 2012, which exhibited a higher 
sensitivity and lower specificity than the ACR criteria [5]. The SLICC criteria include 11 clinical and six immunologic items. Classification criteria require four items with at least one clinical and one immunologic item, or biopsy-proven nephritis compatible with lupus in the presence of an ANA or anti-dsDNA [5]. The SLICC criteria has been validated in children, showing better sensitivity and fewer misclassifications than the ACR criteria [6]. Of note, these are no diagnostic criteria, and some patients need treatment despite not fitting classification criteria.

Children with SLE are at a significantly higher risk of disease damage than adults with SLE [7]. A multidisciplinary therapeutic approach is necessary in order to treat pediatric SLE (pSLE). In this review, we aim to provide and review the recommendations for the management of children with SLE. This article is based on previously conducted studies and does not involve any new studies of human or animal subjects performed by any of the authors.

\section{Quality Indicators for pSLE}

In 2013, an international consensus was reached for the first set of quality indicators for pSLE patients. The consensus resulted in 26 quality indicators for pSLE (Table 1). Although there are similarities to quality indicators proposed for adult SLE, distinct pediatric concerns were incorporated, including high dose glucocorticoid therapy at diagnosis, antibody profile testing, ophthalmology screening, treatment of lupus nephritis, and monitoring for medication safety [3].

\section{Treatment of pSLE}

Medical management of pSLE differs between providers, but will usually have the same principal approach. Most patients will require glucocorticoids and often immunosuppressive drugs, with the aim of reducing disease activity while also preventing long-term toxicities from medications. There are ongoing studies to develop treatment guidelines.

\section{Glucocorticoids}

Glucocorticoids are the mainstay of pharmacological treatment in patients with pSLE with or without major organ involvement. Glucocorticoids are given mainly as oral prednisone, prednisolone, or intravenous high-dose methylprednisolone.

Daily doses of glucocorticoids can vary among providers, and can range from 0.5 to $2 \mathrm{mg} / \mathrm{kg} /$ day. The initial dose is decided by the extent of disease severity and organ involvement. Taper of glucocorticoid doses is usually based on improvement in disease activity, including improving physical exam and symptoms, and response to treatment, with respect to improvement in laboratory parameters. In general, laboratory parameters that help decide whether a decrease in glucocorticoids is warranted include improvements in complement levels (usually to normal), improvement in anti-dsDNA levels, improvement of cytopenias, or other specific laboratory abnormalities such as a decrease in creatinine kinase and decrease in urine protein-to-creatinine ratios.

Intravenous methylprednisolone (IVMP) at a dose of $30 \mathrm{mg} / \mathrm{kg}$ to a $\max$ of $1 \mathrm{~g}$ (for $1-5$ consecutive days) is usually initiated at diagnosis. IVMP helps decrease the IFN signature of disease activity in lupus. Increased expression of IFN-regulated genes, termed the IFN signature, correlates with autoantibodies in lupus [8]. These signatures are not decreased with oral glucocorticoids. The dosing of glucocorticoids is highly variable among 
Table 1 Quality indicators for patients with childhood-onset SLE by domain Hollander et al. [3] with permission from Wiley

Laboratory testing around the time of diagnosis

1. IF a patient has suspected childhood-onset SLE, THEN the following laboratory studies should be obtained (see Table 3$)^{a}$

2. IF a patient has confirmed childhood-onset SLE, THEN the following laboratory studies should be obtained (see Table 3)

\section{General prevention}

3. IF a patient has childhood-onset SLE, THEN vaccination against influenza and encapsulated organisms, including pneumococcus, meningococcus, and Haemophilus influence, should be prescribed, unless there are contraindications

4. IF a patient has childhood-onset SLE, THEN education about sun avoidance should be documented at least once in the medical record (e.g., wearing protective clothing, applying sunscreens whenever outdoors, and avoiding sunbathing) ${ }^{\text {b }}$

5. IF an adolescent has childhood-onset SLE, THEN a transition plan should be carefully designed to facilitate transfer of care to the appropriate adult health care providers

\section{$L N$ and hypertension management}

6. IF a patient has a flare after having achieved remission of kidney disease, THEN diligent follow-up of renal disease is needed

7. IF a patient has newly diagnosed LN, THEN renal biopsy, urine sediment analysis, proteinuria, and kidney function should all be assessed ${ }^{\mathrm{b}}$

8. IF a patient is diagnosed with proliferative childhood-onset SLE nephritis (WHO or ISN/RPS class III or IV), THEN therapy with corticosteroids combined with another immunosuppressive agent should be provided and documented within 1 month of this diagnosis, unless contraindicated ${ }^{\mathrm{b}}$

9. IF a childhood-onset SLE patient without known LN has developed daily proteinuria of $>500 \mathrm{mg}$ or clinically relevant worsening of GFR/urinary sediment, THEN a kidney biopsy should be performed

10. IF a patient has known LN, THEN a clinical assessment for childhood-onset SLE should occur at least every 3 months, regardless of disease activity

11. IF a childhood-onset SLE patient has LN plus evidence of ongoing proteinuria $>500 \mathrm{mg} /$ day, THEN an angiotensin-converting enzyme inhibitor or angiotensin receptor blockers should be prescribed, unless there are contraindications ${ }^{c}$

12. IF a patient has LN and/or hypertension, THEN disease comanagement with a nephrologist should be considered

\section{Medication management}

13. IF a patient is prescribed a new medication for childhood-onset SLE (e.g., NSAIDs, DMARDs, or glucocorticoids), THEN a discussion with the patient about the risks versus benefits of the chosen therapy should be documented ${ }^{\mathrm{b}}$

14. IF a patient has childhood-onset SLE, THEN antimalarial therapy should be prescribed, unless there are contraindications

15. IF a childhood-onset SLE patient is receiving a dose of steroids not acceptable for long-term use, then an attempt should be made to taper steroids ${ }^{b}$ 
Table 1 continued

16. IF a patient with childhood-onset SLE is unable to decrease the dose of steroids acceptable for long-term use, THEN the addition of a steroid-sparing agent or an increased dose of an existing steroid-sparing agent should be considered ${ }^{\mathrm{b}}$

17. IF a childhood-onset SLE patient is treated with medications, THEN laboratory surveillance for medication safely should done at regular intervals (details provided in Table 4$)^{\mathrm{b}}$

Bone bealth

18. IF a patient has received chronic systemic steroids, THEN the patient should have bone mineral density testing documented in the medical record

19. IF baseline bone mineral density testing is outside of the normal limits ( $Z$ scores of -2 or less), THEN bone mineral density should be remeasured after 1 year

20. IF a patient is receiving any steroid therapy, THEN calcium and vitamin D supplementation should be recommended after 3 months

Ophthalmologic surveillance

21. IF a childhood-onset SLE patient is treated with corticosteroids, THEN eye screening should be done at least annually

22. IF a childhood-onset SLE patient is treated with antimalarial therapy. THEN eye screening should be done at least annually

Education on cardiovascular risk factors

23. IF a patient has childhood-onset SLE, THEN education about cardiovascular risk factors should occur in regular intervals with the parent and the patient age $\geq 13$ years (see Table 5 )

24. IF a patient has childhood-onset SLE, THEN lifestyle modifications (smoking cessation, weight control, exercise) are likely to be beneficial for patient outcomes and should be encouraged ${ }^{\mathrm{b}}$

Pregnancy

25. IF a patient with childhood-onset SLE is pregnant, THEN anti-SSA, anti-SSB, and antiphospholipid antibodies should be documented in the medical record ${ }^{\mathrm{b}}$

\section{Neuropsychiatric manifestations}

26. IF a patient with childhood-onset SLE has major neuropsychiatric manifestations (optic neuritis, acute confused state/coma, cranial or peripheral neuropathy, psychosis, and transverse myelitis/myelopathy), THEN immunosuppressive therapy should be considered ${ }^{\mathrm{b}}$

SLE systemic lupus erythematosus, $L N$ lupus nephritis, WHO World Health Organization, ISN/RPS International Society of Nephrology/Renal Pathology and Society, GFR glomerular filtration rate, NSAIDs nonsteroidal anti-inflammatory drugs, $D M A R D s$ diseases-modifying antirheumatic drugs

a Suspected SLE is often defined as fulfilling three of 11 criteria for lupus diagnosis as defined by the American College of Rheumatology

b Adult quality indicators (endorsed by the American College of Rheumatology or the European League Against Rheumatism) that achieved consensus for childhood-onset SLE

c Ongoing proteinuria is defined as persistence of proteinuria for $\geq 3$ months

pediatric rheumatologists. There have been initiatives to attempt to standardize steroid treatment, particularly for lupus nephritis
(LN). In 2012, the Childhood Arthritis Rheumatology Research Alliance published consensus treatment plans for induction 
therapy of LN [9]. These guidelines can be found in Fig. 1. Cyclophosphamide and mycophenolate mofetil, both of which are a part of these guidelines, will be discussed later in this review. Early side effects of steroids include endocrine manifestations such as hyperglycemia and weight gain, which are reversible with tapering but may lead to diabetes mellitus, obesity, hypertension, hyperlipidemia, and atherosclerosis [10]. While on steroids, it is important to track height and weight, which should improve as steroid therapy is tapered or discontinued. Physical body changes, including Cushingoid features and striae, should be discussed often with patients. A healthy diet low in salt should be reiterated to prevent fluid retention and hypertension. Long-term glucocorticoids can also cause osteoporosis, so along with adequate calcium and vitamin $\mathrm{D}$ intake, a bone mineral density scan is performed annually [11]. Glucocorticoids can also cause cataracts and increased risk of glaucoma, which may lead to visual field loss and even blindness [12].

\section{Hydroxychloroquine}

Hydroxychloroquine is an antimalarial agent given to almost all patients with adult or pediatric SLE. Hydroxychloroquine inhibits Toll-like receptor pathways and minimizes flare, treats skin disease, and decreases the rate of autoantibody production [13, 14,]. The usual prescribed dose of hydroxychloroquine is 4-6/ $\mathrm{mg} / \mathrm{kg} /$ day. Additionally, hydroxychloroquine has an important role in cardiovascular protection, such as anti-platelet, anti-thrombotic, lipid-regulating,

\begin{tabular}{|c|c|c|c|c|c|c|c|c|c|c|c|c|}
\hline \multicolumn{13}{|c|}{$\begin{array}{l}\text { SELECTION OF IMMUNOSUPPRESSIVE AGENT (pick } 1 \text { of these } 2 \text { ) } \\
\text { Cyclophosphamide IV q } 4 \text { weeks for } 6 \text { months } \\
\text {-OR- } \\
\text { cophenolate mofetil } 600 \mathrm{mg} / \mathrm{m} 2 / \text { dose PO BID ( } \max 3,000 \mathrm{mg} / \mathrm{d} \text { ) for } 6 \mathrm{months} \\
\text { te Mycophenolate sodium } 400 \mathrm{mg} / \mathrm{m} 2 / \mathrm{dose} \text { PO BID [max } 1,080 \mathrm{mg} \text { BID] for } 6 \text { months) }\end{array}$} \\
\hline \multicolumn{13}{|c|}{ SELECTION OF STEROID REGIMEN (pick 1 of these 3) } \\
\hline \multicolumn{3}{|c|}{ Primarily ORAL - } & \multirow[t]{3}{*}{ OR } & \multicolumn{4}{|c|}{ PRIMARILYN } & \multirow[t]{11}{*}{ OR } & \multicolumn{4}{|c|}{ MIXXED ORALNV } \\
\hline $\begin{array}{l}\text { Week } \\
\text { (wk) }\end{array}$ & $\begin{array}{l}\text { Daily } \\
\text { dose } \\
>30 \mathrm{~kg} \\
\text { (mg) }\end{array}$ & $\begin{array}{l}\text { Daily dose } \\
\leq 30 \mathrm{~kg}\end{array}$ & & Week & $\begin{array}{l}\text { \# Steroid } \\
\text { pulsest }\end{array}$ & $\begin{array}{l}\text { Daily } \\
\text { dose } \\
>30 \mathrm{~kg} \\
(\mathrm{mg})\end{array}$ & $\begin{array}{l}\text { Daily } \\
\text { dose } \\
\leq 30 \mathrm{~kg} \\
\text { (mg) }\end{array}$ & & Week & $\begin{array}{c}\text { \# } \\
\text { Steroid } \\
\text { pulsest }\end{array}$ & $\begin{array}{l}\text { Dailly } \\
\text { dose } \\
>30 \mathrm{~kg} \\
(\mathrm{mg})\end{array}$ & $\begin{array}{l}\text { Daily } \\
\text { dose } \\
\leq 30 \mathrm{~kg} \\
(\mathrm{mg} / \mathrm{kg} / \mathrm{d})\end{array}$ \\
\hline $1-4$ & $60-80$ & $2 \mathrm{mg} / \mathrm{kg} / \mathrm{d}$ & & 1 & 3/wk & 20 & 10 & & 1 & $3 / w k$ & 60 & 1.5 \\
\hline 5-6 & 60 & $2 \mathrm{mg} / \mathrm{kg} / \mathrm{d}$ & & 2 & 1-3 wk & 20 & 10 & & 2 & & 60 & 1.5 \\
\hline $7-10$ & so & $\underset{\mathrm{mg}}{+ \text { by 5-10 }}$ & & 3 & 1-3 wk & 20 & 10 & & 3 & (mo) & 50 & 1.2 \\
\hline $11-12$ & 40 & $\downarrow$ by $5 \mathrm{mg}$ & & 4 & $1-3 / \mathrm{wk}$ & 20 & 10 & & 4 & & 40 & 1 \\
\hline $13-14$ & 40 & 1 by $5 \mathrm{mg}$ & & $5-7$ & $1-3 / w k$ & 20 & 10 & & $5-8$ & $1 / \mathrm{mo}$ & 35 & 0.9 \\
\hline $15-18$ & 30 & $\downarrow$ by $5 \mathrm{mg}$ & & $8-11$ & $1 / \mathrm{mo}$ & 20 & 10 & & $9-12$ & $1 / \mathrm{mo}$ & 30 & 0.8 \\
\hline $19-22$ & 25 & $\underset{\mathrm{mg}}{4 \text { by } 2.5-5}$ & & $12-18$ & $1 / \mathrm{mo}$ & 15 & 7.5 & & $13-16$ & $1 / \mathrm{mo}$ & 25 & 0.7 \\
\hline $23-24$ & 20 & $\underset{\mathrm{mg}}{+ \text { by } 2.5-5}$ & & $19-24$ & $1 / \mathrm{mo}$ & 10 & 5 & & $17-20$ & $1 / \mathrm{mo}$ & 20 & 0.6 \\
\hline \multicolumn{3}{|c|}{$\begin{array}{l}\text { Optional } 3 \text { day pulse in week } \\
1 \text { is permitted }\end{array}$} & & & & & & & $21-24$ & $1 / \mathrm{mo}$ & 15 & 0.5 \\
\hline
\end{tabular}

Fig. 1 Consensus treatment plan for proliferative juvenile systemic lupus erythematosus-associated lupus nephritis (Source: [9]) with permission from Wiley 
anti-hypertensive, hypoglycemic properties, which are important to consider in SLE patients [15]. This adjunctive treatment is usually continued for a prolonged period of time. Patients require ophthalmological screening for hydroxychloroquine induced retinopathy, which can present insidiously with subtle color vision changes and paracentral scotoma, making early detection difficult [16]. Early screening is important to possibly arrest its progression, thereby averting or lessening visual loss [17].

\section{Mycophenolate Mofetil}

Mycophenolate mofetil has been a heavily studied drug, particularly in the treatment of lupus nephritis. Trials in adults have demonstrated that mycophenolate mofetil has equivalent or better results than cyclophosphamide [18]. Studies have also shown that mycophenolate mofetil has lower rates of adverse effects, particularly infections, for the 6-month induction phase and long-term maintenance in comparison to cyclophosphamide [19]. The usual dosage of mycophenolate mofetil is $600 \mathrm{mg} / \mathrm{m}^{2} /$ dose twice daily with a maximum dosage of $1500 \mathrm{mg}$ taken two times per day [9]. MMF can also be used as a steroid sparing agent in dermatological manifestations of SLE. Side effects of mycophenolate mofetil include mild gastrointestinal symptoms, cytopenias, and teratogenicity. It is important to note that African Americans may require higher doses of mycophenolate mofetil due to increased clearance of the drug [20]. Urine pregnancy tests are done while on MMF and patients should be appropriately counseled on fetal toxicity and teratogenicity. With evidence of increased risk of miscarriage and birth defects associated with MMF use, the FDA instituted a
REMS program that contains both a medication guide and elements to assure safe use [21].

\section{Cyclophosphamide}

Cyclophosphamide is primarily used for the management of severe SLE, including lupus nephritis, life-threatening organ involvement, and neuropsychiatric manifestations. Cyclophosphamide has been a well-established treatment for lupus nephritis for many years [22]. In lupus nephritis induction therapy, intravenous cyclophosphamide is given every 4 weeks for 6 months [8]. The European protocol for treating lupus nephritis, which consists of low-dose IV cyclophosphamide (500 mg) every 2 weeks for six doses, has also proven to be an effective initial treatment regimen [23].

It is important to counsel female patients about fertility issues. SLE patients exposed to cyclophosphamide have a much higher risk of developing infertility and premature ovarian failure than do the counterparts who are treated with other less-toxic treatments [24]. Cyclophosphamide can permanently alter the ovarian reserve in a manner that is dose-, duration-, and age-dependent, and patients should be counseled to use effective contraception until the end of treatment, and a minimum of one ovulation cycle after the end of treatment is recommended before considering conception [25]. Patients can consider GnRH agonists to prevent cycles. It was initially thought that cyclophosphamide led to increased infections. These infections, when thought to be related to cyclophosphamide therapy, have been in the setting of cyclophosphamide-induced reductions in total WBC count [26]. However, current literature supports that the current recommended regimens significantly lower 
adverse effects like infections whilst not affecting efficacy [27]. It is important to counsel patients of an increased risk of bladder cancer with the use of cyclophosphamide, which has been found to be dose-dependent.

\section{Azathioprine}

Azathioprine is used to help treat lupus nephritis, as well as dermatologic and hematologic manifestations of pSLE [28]. Thiopurine methyltransferase (TPMT), an enzyme that metabolizes azathioprine, can be tested in order to titrate dosing to prevent azathioprine toxicity. Azathioprine is a category $\mathrm{D}$ drug, so there is positive evidence of risk during pregnancy. It should be continued during pregnancy if the benefits outweigh the risks. There is also an increased risk of cancers, particularly skin cancers and lymphomas, with use of azathioprine. Blood test monitoring is important in detecting azathioprine-related toxicity. Neutropenia, lymphopenia, and deranged liver function may be relevant and indicate myelotoxicity, susceptibility to infection, and hepatotoxicity, respectively [29].

\section{Rituximab}

An anti-CD20 monoclonal antibody, rituximab, targets B-cells and their ability for antibody production. Studies have shown that that rituximab is particularly effective in treating SLE-associated cytopenias [30]. In patients with severe SLE organ involvement, benefit has been shown in using rituximab and cyclophosphamide together [31]. Prior to initiating therapy with rituximab, $\mathrm{CBC}$ with flow cytometry, quantitative immunoglobulins, and vaccine titers are usually obtained. Patients should be carefully monitored due to increased risk of infections. Serum immunoglobulin levels and flow cytometry are important labs to monitor after B cell depletion and can help decide whether to continue
anti-CD20 monoclonal antibody therapy [32]. Patients may require IVIG replacement therapy for hypogammaglobulinemia.

\section{Vitamin D and Calcium}

Patients should be counseled and monitored for proper intake of Vitamin D and calcium. Long term use of glucocorticoids and renal disease make adequate Vitamin D and calcium intake even more important.

\section{Potential Future Therapies}

Belimumab was approved in the USA and Europe in 2011 for the treatment of adults with autoantibody-positive SLE [33]. Current trials are studying its use in pSLE. Belimumab is a human IgG1 monoclonal antibody that binds to soluble BLyS and inhibits its biological activity. Increased BLyS levels are associated with greater disease activity in SLE. BLyS may increase the ability of autoreactive B cells to escape regulatory mechanisms and differentiate into autoantibody-secreting plasma cells [34]. Belimumab has been shown to be effective in autoantibody-positive adult SLE patients with moderately active disease whose clinical manifestations are predominantly mucocutaneous and/or musculoskeletal and emerging data confirms that pSLE patients with similar characteristics also respond favorably to belimumab, in particular, suggesting a potential role for belimumab as a steroid-sparing agent [35].

Another pathway developing for lupus treatment is the mTOR blockade with the use of rapamycin. This is currently being studied to treat refractory lupus in children. Rapamycin blocks $\mathrm{T}$ cell activation in patients with SLE with remarkable therapeutic efficacy since the activation of mTORC1 preceded disease flares and responded to therapeutic intervention with rapamycin [36]. 
Other future therapies target IFN-regulated genes. Chronic activation of the innate immune system in SLE, including upregulated IFN-regulated genes (IFN signature), has led to the development of biologic agents targeting this cytokine in SLE [37].

\section{Barriers to Treatment}

A multidisciplinary approach is needed to provide best practices in the care of pSLE patients. Social and psychological problems, mood changes and depression, disease complications, or drug-related issues are common in teenagers with chronic diseases such as lupus, and require special attention by psychologists and social workers [38]. Appropriately educating pSLE patients and involving them in their care plan is essential. Pediatric patients with rheumatic diseases may not be sufficiently engaged in their medical care or unwilling to engage, and therefore lack understanding of the purposes of their medications [39]. Encouraging patients to develop self-care skills, especially as they transition to adult care, is important. Non-adherence is associated with poorer health perceptions, self-esteem, mental health, family cohesion, and social functioning [40]. Psychosocial and educational interventions targeted at improving confidence, self-efficacy, disease-related knowledge, social support, and resolving insecurities regarding patients' capacity for self-management may alleviate psychosocial distress and improve adherence and health outcomes of adolescents and young adults with SLE [41].

Transition of care is an important time in a pSLE patient's life. The successful transition from pediatric to adult care for patients with chronic conditions is predicated on the ability of the individual to achieve self-efficacy and disease self-management skills as well as the ability of the medical system to provide patient-centered care [42]. A recent study regarding transition of SLE patients showed that transfer of care from pediatric to adult providers was characterized by moderately high disease activity, prolonged time between the last pediatric and first adult provider appointments, and frequent gaps in care [42]. Major challenges with transition of pSLE patients are loss of insurance and attachment to pediatric providers [43]. This supports the need for a structured transition process that helps prepare patients for the expectations of adult care. Continued follow-up studies are needed to solidify strategies that will be proven to be successful over a long period of time.

\section{CONCLUSIONS}

Providing care for pSLE patients is a unique experience. It is important to consider each patient's particular SLE manifestations to provide proper care. Advances in treatment options provided better disease responses and effective control of disease activity. Chronic burden of illness, psychosocial factors, and medication adherence all make this journey challenging. Increasing knowledge of the pathogenesis of SLE and autoimmune processes will help target new and innovative therapies.

It is also imperative to prepare patients for differences in autonomy of care as they eventually transition to adult care. Adult providers should be sensitive to patients who are used to a pediatric clinical experience. In turn, pediatric practitioners need to provide patients with ownership of their disease, education about pSLE and medications, and an understanding that a diagnosis of pSLE is a lifelong challenge. 


\section{ACKNOWLEDGMENTS}

No funding or sponsorship was received for the publication of this article. All named authors meet the International Committee of Medical Journal Editors (ICMJE) criteria for authorship for this manuscript, take responsibility for the integrity of the work as a whole, and have given final approval for the version to be published.

Disclosures. A. Thakral and M. S. Klein-Gitelman have nothing to disclose.

Compliance with Ethics Guidelines. This article is based on previously conducted studies and does not involve any new studies of human or animal subjects performed by any of the authors.

Open Access. This article is distributed under the terms of the Creative Commons Attribution-NonCommercial 4.0 International License (http://creativecommons.org/licenses/ by-nc/4.0/), which permits any noncommercial use, distribution, and reproduction in any medium, provided you give appropriate credit to the original author(s) and the source, provide a link to the Creative Commons license, and indicate if changes were made.

\section{REFERENCES}

1. Barsalou J, Levy DM, Silverman ED. An update on childhood-onset systemic lupus erythematosus. Curr Opin Rheumatol. 2013;25(5):616-22.

2. Brunner HI, Huggins J, Klein-Gitelman MS. Pediatric SLE-towards a comprehensive management plan. Nat Rev Rheumatol. 2011;7(4):225-33.

3. Hollander MC, Sage JM, Greenler AJ, Pendl J, Avcin $T$, Espada $G$, et al. International consensus for provisions of quality-driven care in childhood-onset systemic lupus erythematosus. Arthritis Care Res. 2013;65(9):1416-23.
4. Hochberg MC. Updating the American College of Rheumatology revised criteria for the classification of systemic lupus erythematosus. Arthritis Rheum. 1997;40(9):1725.

5. Petri M, Orbai AM, Alarcon GS, Gordon C, Merrill JT, Fortin PR, et al. Derivation and validation of the Systemic Lupus International Collaborating Clinics classification criteria for systemic lupus erythematosus. Arthritis Rheum. 2012;64(8):2677-86.

6. Sag E, Tartaglione A, Batu ED, Ravelli A, Khalil SM, Marks SD, et al. Performance of the new SLICC classification criteria in childhood systemic lupus erythematosus: a multicentre study. Clin Exp Rheumatol. 2014;32(3):440-4.

7. Hersh AO, Trupin L, Yazdany J, Panopalis P, Julian L, Katz P, et al. Childhood-onset disease as a predictor of mortality in an adult cohort of patients with systemic lupus erythematosus. Arthritis Care Res. 2010;62(8):1152-9.

8. Guiducci C, Gong M, Xu Z, Gill M, Chaussabel D, Meeker T, et al. TLR recognition of self nucleic acids hampers glucocorticoid activity in lupus. Nature. 2010;465(7300):937-41.

9. Mina R, von Scheven E, Ardoin SP, Eberhard BA, Punaro $\mathrm{M}$, Ilowite $\mathrm{N}$, et al. Consensus treatment plans for induction therapy of newly diagnosed proliferative lupus nephritis in juvenile systemic lupus erythematosus. Arthritis Care Res. 2012;64(3):375-83.

10. Kasturi S, Sammaritano LR. Corticosteroids in lupus. Rheum Dis Clin N Am. 2016;42(1):47-62.

11. Lam NC, Ghetu MV, Bieniek ML. Systemic lupus erythematosus: primary care approach to diagnosis and management. Am Fam Physician. 2016;94(4):284-94.

12. Ruiz-Irastorza G, Danza A, Khamashta M. Glucocorticoid use and abuse in SLE. Rheumatology. 2012;51(7):1145-53.

13. Costedoat-Chalumeau N, Amoura Z, Hulot JS, Hammoud HA, Aymard G, Cacoub P, et al. Low blood concentration of hydroxychloroquine is a marker for and predictor of disease exacerbations in patients with systemic lupus erythematosus. Arthritis Rheum. 2006;54(10):3284-90.

14. Bertsias GK, Tektonidou M, Amoura Z, Aringer M, Bajema I, Berden JH, et al. Joint European League Against Rheumatism and European Renal Association-European Dialysis and Transplant Association (EULAR/ERA-EDTA) recommendations for the management of adult and paediatric lupus nephritis. Ann Rheum Dis. 2012;71(11):1771-82. 
15. Sun L, Liu M, Li R, Zhao Q, Liu J, Yang Y, et al. Hydroxychloroquine, a promising choice for coronary artery disease? Med Hypotheses. 2016;93:5-7.

16. Shulman S, Wollman J, Brikman S, Padova $H$, Elkayam O, Paran D. Implementation of recommendations for the screening of hydroxychloroquine retinopathy: poor adherence of rheumatologists and ophthalmologists. Lupus. 2016. doi:10.1177/0961203316660204.

17. Marmor MF, Hu J. Effect of disease stage on progression of hydroxychloroquine retinopathy. JAMA ophthalmology. 2014;132(9):1105-12.

18. Ginzler EM, Dooley MA, Aranow C, Kim MY, Buyon $\mathrm{J}$, Merrill JT, et al. Mycophenolate mofetil or intravenous cyclophosphamide for lupus nephritis. N Engl J Med. 2005;353(21):2219-28.

19. Contreras G, Pardo V, Leclercq B, Lenz O, Tozman E, O'Nan P, et al. Sequential therapies for proliferative lupus nephritis. $\mathrm{N}$ Engl J Med. 2004;350(10):971-80.

20. Tornatore KM, Meaney CJ, Wilding GE, Chang SS, Gundroo A, Cooper LM, et al. Influence of sex and race on mycophenolic acid pharmacokinetics in stable African American and Caucasian renal transplant recipients. Clin Pharmacokinet. 2015;54(4):423-34.

21. Rostas S, Kim M, Gabardi S. Risk evaluation and mitigation strategies: a focus on the mycophenolic acid preparations. Prog Transpl. 2014;24(1):33-6.

22. Sinha R, Raut S. Pediatric lupus nephritis: management update. World J Nephrol. 2014;3(2):16-23.

23. Houssiau FA, Vasconcelos C, D'Cruz D, Sebastiani GD, de Ramon Garrido E, Danieli MG, et al. The 10-year follow-up data of the euro-lupus nephritis trial comparing low-dose and high-dose intravenous cyclophosphamide. Ann Rheum Dis. 2010;69(1):61-4.

24. Oktem O, Guzel Y, Aksoy S, Aydin E, Urman B. Ovarian function and reproductive outcomes of female patients with systemic lupus erythematosus and the strategies to preserve their fertility. Obstet Gynecol Surv. 2015;70(3):196-210.

25. Leroy C, Rigot JM, Leroy M, Decanter C, Le Mapihan $\mathrm{K}$, Parent AS, et al. Immunosuppressive drugs and fertility. Orphanet J Rare Dis. 2015;10:136.

26. Pryor BD, Bologna SG, Kahl LE. Risk factors for serious infection during treatment with cyclophosphamide and high-dose corticosteroids for systemic lupus erythematosus. Arthritis Rheum. 1996;39(9):1475-82.

27. Haga HJ, D'Cruz D, Asherson R, Hughes GR. Short term effects of intravenous pulses of cyclophosphamide in the treatment of connective tissue disease crisis. Ann Rheum Dis. 1992;51(7):885-8.

28. Thompson AJ, Newman WG, Elliott RA, Roberts SA, Tricker K, Payne K. The cost-effectiveness of a pharmacogenetic test: a trial-based evaluation of TPMT genotyping for azathioprine. Value Health J Int Soc Pharmacoecon Outcomes Res. 2014;17(1):22-33.

29. Meggitt SJ, Anstey AV, Mohd Mustapa MF, Reynolds NJ, Wakelin S. British Association of Dermatologists' guidelines for the safe and effective prescribing of azathioprine 2011. Br J Dermatol. 2011;165(4):711-34.

30. Abdwani R, Mani R. Anti-CD20 monoclonal antibody in acute life threatening haemolytic anaemia complicating childhood-onset SLE. Lupus. 2009;18(5):460-4.

31. Illei GG, Cervera R, Burt RK, Doria A, Hiepe F, Jayne $D$, et al. Current state and future directions of autologous hematopoietic stem cell transplantation in systemic lupus erythematosus. Ann Rheum Dis. 2011;70(12):2071-4.

32. Reddy V, Martinez L, Isenberg DA, Leandro MJ, Cambridge G. Pragmatic treatment of patients with Systemic Lupus Erythematosus with rituximab: Long-term effects on serum immunoglobulins. Arthritis Care Res. 2016. doi:10.1002/acr.22993.

33. Weintraub B. Belimumab efficacy is 'mild' but market potential still greatdagger: anticipating us approval of the first lupus drug since 1957. BioDrugs Clin Immunother Biopharm Gene Ther. 2011;25(3):203-5.

34. Do RK, Hatada E, Lee H, Tourigny MR, Hilbert D, Chen-Kiang S. Attenuation of apoptosis underlies B lymphocyte stimulator enhancement of humoral immune response. J Exp Med. 2000;192(7):953-64.

35. Hui-Yuen JS, Nguyen SC, Askanase AD. Targeted B cell therapies in the treatment of adult and pediatric systemic lupus erythematosus. Lupus. 2016;25(10):1086-96.

36. Fernandez D, Bonilla E, Mirza N, Niland B, Perl A. Rapamycin reduces disease activity and normalizes $\mathrm{T}$ cell activation-induced calcium fluxing in patients with systemic lupus erythematosus. Arthritis Rheum. 2006;54(9):2983-8. 
37. Postal M, Costallat LT, Appenzeller S. Biological therapy in systemic lupus erythematosus. Int J Rheumatol. 2012;2012:578641.

38. Falcini F, Nacci F. Systemic lupus erythematosus in the young: the importance of a transition clinic. Lupus. 2007;16(8):613-7.

39. Lawson EF, Hersh AO, Applebaum MA, Yelin EH, Okumura MJ, von Scheven E. Self-management skills in adolescents with chronic rheumatic disease: a cross-sectional survey. Pediatr Rheumatol Online J. 2011;9(1):35.

40. Fredericks EM, Magee JC, Opipari-Arrigan L, Shieck V, Well A, Lopez MJ. Adherence and health-related quality of life in adolescent liver transplant recipients. Pediatr Transplant. 2008;12(3):289-99.
41. Tunnicliffe DJ, Singh-Grewal D, Chaitow J, Mackie F, Manolios N, Lin MW, et al. Lupus means sacrifices: perspectives of adolescents and young adults with systemic lupus erythematosus. Arthritis Care Res. 2016;68(6):828-37.

42. Son MB, Sergeyenko Y, Guan H, Costenbader KH. Disease activity and transition outcomes in a childhood-onset systemic lupus erythematosus cohort. Lupus. 2016. doi:10.1177/ 0961203316640913.

43. Felsenstein S, Reiff AO, Ramanathan A. Transition of care and health-related outcomes in pediatric-onset systemic lupus erythematosus. Arthritis Care Res. 2015;67(11):1521-8. 